\title{
EVALUACIÓN DE LA PECTINA EXTRAÍDA ENZIMÁTICAMENTE A PARTIR DE LAS CÁSCARAS DEL FRUTO DE CACAO (Theobroma cacao L.)
}

\section{EVALUATION OF PECTIN EXTRACTED ENZYMATICALLY FROM COCOA (Theobroma cacao L.) POD HUSKS}

\author{
Lina Mendoza-Vargas ${ }^{1}$, Javier Jiménez-Forero ${ }^{2 *}$, Miguel Ramírez-Niño ${ }^{3}$
}

\begin{abstract}
${ }^{1}$ Ingeniero(a) Agroindustrial, Joven investigadora, Grupo de Investigación Ciencia, Tecnología e Innovación Agroindustrial CITIA. Universidad de los Llanos, Villavicencio, Colombia, e-mail: lina.mendoza@unillanos.edu.co; ${ }^{2}$ Ingeniero de Producción Agroindustrial, Magíster en diseño y gestión de procesos, Profesor tiempo completo, Facultad de Ciencias Agropecuarias y Recursos Naturales, Grupo de Investigación Ciencia, Tecnología e Innovación Agroindustrial CITIA. Universidad de los Llanos, Villavicencio, Colombia, e-mail: jajimenez@unillanos.edu.co; ${ }^{3}$ Químico, Magíster en Ciencia y Tecnología de Alimentos, Profesor tiempo completo, Facultad de Ciencias Básicas e Ingeniería. Universidad de los Llanos, Villavicencio, Colombia, e-mail: miguelramirez@unillanos.edu.co
\end{abstract}

Rev. U.D.C.A Act. \& Div. Cient. 20(1): 131-138, Enero-Junio, 2017

\section{RESUMEN}

La presente investigación tuvo como propósito evaluar el rendimiento y las características de la pectina extraída enzimáticamente a partir de la cáscara, pericarpio del fruto de cacao (Theobroma cacao L.); para ello, se realizó un diseño de tipo unifactorial, con 4 niveles de tratamiento, variando la concentración de complejo enzimático comercial Viscozyme L., de la marca Novozyme ${ }^{\circledR}$. La pectina obtenida fue caracterizada, de acuerdo a la metodología planteada por Owens et al. 1952. Se elaboró un producto comercial tipo conserva (mermelada), donde se comparó la pectina obtenida enzimáticamente, con pectina comercial de alto y bajo metoxilo; en ambos casos fue evaluada la viscosidad aparente del fluido obtenido. Como resultados, se obtuvo mayor rendimiento de extracción de pectina promedio $(13,0 \pm 0,53 \%)$, utilizando la mayor concentración de complejo enzimático $(82,9 \mu \mathrm{L} / 100 \mathrm{~g}$ cáscara), presentando diferencias significativas con los demás tratamientos $(\mathrm{p}<0,05)$; el porcentaje de metóxilo $(\mathrm{ME})$ fue de $1,58 \pm 0,01 \%$, el peso equivalente (PE) $5091,4 \pm 77,6$ $\mathrm{mg} / \mathrm{meq}$; la acidez libre (AL) 0,20 $\pm 0,01 \mathrm{meq} / \mathrm{g}$; el grado de esterificación (GE) $72 \pm 0,1 \%$ y el porcentaje de ácido anhídridogalacturónico (AAG) $12,5 \pm 1,0 \%$. Con respecto al producto comercial, se observaron características reológicas de un fluido no Newtoniano pseudoplástico, con una viscosidad aparente máxima de 6043,7 mPa.s y mínima de 1741,3 mPa.s, al aumentar la fuerza del torque, presentando una menor capacidad viscosante que la pectina comercial. De acuerdo a los resultados obtenidos, se demostró que existe la oportunidad de obtener pectinas a partir de residuos del sector cacaotero, utilizando enzimas comerciales, con posibles usos en la industria alimentaria.
Palabras clave: Rendimiento de extracción, hidrólisis enzimática, viscosidad, grado de esterificación, grado de metoxilación y cáscara de cacao.

\section{SUMMARY}

This research was aimed to evaluate the yield and characteristics of pectin extracted enzymatically from cocoa (Theobroma cacao L.) pod husks pericarp. For this a unifactorial type design with 4 levels of treatment varying the concentration of commercial enzyme complex Viscozyme L. of the brand Novozyme ${ }^{\circledR}$.. The obtained pectin was characterized according to the methodology proposed by Owens et al. 1952. A commercial preserved product (jam) was elaborated, where pectin obtained enzymatically was compared with high and low methoxyl commercial pectin, in both cases the apparent viscosity of the obtained fluid was evaluated. The highest pectin extraction yield (13.0 \pm $0.53 \%$ ) was obtained using the highest concentration of enzyme complex (82.9 $\mu \mathrm{L} / 100 \mathrm{~g}$ shell), showing significant differences with the other treatments $(p<0,05)$. Percentage of methoxyl $(\mathrm{ME})$ was $1.58 \pm 0.01 \%$, equivalent weight $(\mathrm{PE})$ $5091.4 \pm 77.6 \mathrm{mg} / \mathrm{meq}$, free acidity (AL) $0.20 \pm 0.01 \mathrm{meq} / \mathrm{g}$, degree of Esterification (GE) $72 \pm 0.1 \%$ and the percentage of anhydridogalacturonic acid (AAG) $12.5 \pm 1.0 \%$. With respect to the commercial product, rheological characteristics of a pseudoplastic non-Newtonian fluid with a maximum apparent viscosity of $6043,7 \mathrm{mPa} . \mathrm{s}$ and a minimum of $1741,3 \mathrm{mPa} . \mathrm{s}$ were observed when increasing the torque force, presenting a lower viscosity capacity than the commercial pectin. According to the results obtained it was demonstrated that there is an opportunity to obtain pectins from residues from 
the cocoa sector using commercial enzymes with possible uses in the food industry.

Key words: Extraction yield, enzymatic hydrolysis, viscosity, esterification and methoxylation degree and cocoa pod husk.

\section{INTRODUCCIÓN}

La producción de semilla de cacao (Theobroma cacao L.), se encuentra, principalmente, en países africanos, con un aporte, aproximado, del $70 \%$. En varios países de Latinoamérica, la producción se centra en cacao fino de sabor y aroma, para elaboración de chocolatería fina, donde su producción supera el $80 \%$, a nivel internacional (International Cocoa Organization, 2012), siendo de gran interés para Colombia, porque, además, se ha convertido en apuesta gubernamental para la sustitución de cultivos ilícitos, en varios departamentos, entre ellos, el del Meta. El plan nacional de desarrollo cacaotero, al 2021, tiene como objetivo un total de 230.000ha productivas, de las cuales, se espera una participación del departamento del Meta, de 16.000ha. En este departamento, de 6.180,5ha sembradas, 3.557 están en producción, con un rendimiento aproximado de 0,6t de semilla por hectárea (Fedecacao, 2015) que, cuantificados, representan 2.101t de semilla/año.

El pericarpio o comúnmente denominado "cáscara" representa, en promedio, entre el $52-76 \%$ del total de la mazorca (Chan \& Choo, 2013), lo que genera alrededor de $10.505 \mathrm{t}$ de cáscara/año, utilizadas, principalmente, como material orgánico para la fertilización de los propios cultivos (Ministerio de Agricultura y Desarrollo Rural, 2012), siendo, quizás, vector de enfermedades, tales como Phytophthorasp. y Oomycetes, lo que conlleva a importantes pérdidas anuales y al incremento del uso de agroquímicos, desinfectantes, herramientas y mano de obra (Jaimes Suárez \& Aranzazu Hernández, 2010); sin embargo, diversas investigaciones proponen su utilización como fuente de energía renovable (Syamsiro et al. 2012), material bioremediador (Pua et al. 2013), fuente de lipasas (Khanahmadi et al. 2016) y fuente de pectina, empleando ácidos fuertes para su extracción, como ácido clorhídrico y acético (Vriesmann et al. 2011).

Las sustancias pécticas presentes en los vegetales, se encuentran en el tejido parenquimático y meristemático, siendo las zonas de mayor concentración, la pared primaria de las células y la lámina media (Willats et al. 2001). La fruta en estado de madurez "verde" posee la sustancia péctica (protopectina), que está asociada a la estructura de la membrana celular por medio de enlaces covalentes y puentes de hidrógeno con la celulosa, hemicelulosa y lignina, principalmente, hallándose altamente esterificada por grupos metóxilo, que la hacen insoluble y confiriéndole rigidez a las cáscaras; sin embargo, durante la maduración del fruto de cacao, se altera la estructura de la cáscara, por acción de enzimas presentes naturalmente, produciendo desesterificación de los grupos metóxilos, convirtiéndola en pectina soluble y favoreciendo el ablandamiento de la cáscara (Brett \& Waldron, 1990; Fredes Monsalves et al. 2009; Kashyap et al. 2001).

La pectina es un heteropolisacárido de origen vegetal compuesto, principalmente, por ácido D-galacturónico, unido mediante enlaces $\alpha$ - $(1,4)$ glucosídicos, que componen la cadena principal. La esterificación que presenta, indica el porcentaje de residuos del ácido galacturónico esterificado o metoxilado por el grupo metilo y se clasifican en pectinas de bajo $(<50 \%)$ y alto metóxilo $(>50 \%)$. Las pectinas forman geles en presencia de iones de calcio y de azúcar, en condiciones de bajo $\mathrm{pH}$, característica importante para su utilización como aditivo en procesos de gelificación (Chan \& Choo, 2013; Chasquibol \& Morales, 2010).

Actualmente, la pectina se obtiene, a escala industrial, de manera tradicional, por hidrólisis con ácidos fuertes, principalmente de origen inorgánico, de difícil recuperación al finalizar el proceso y que impactan al medio ambiente, al acidificar los efluentes y los suelos, si no se disponen de una manera adecuada (Vriesmann et al. 2011).

Por esta razón, en este estudio, se evaluó el rendimiento y se caracterizó la pectina extraída de la cáscara de la mazorca de cacao utilizando un complejo enzimático comercial, con el fin de aprovechar los residuos del beneficio de cacao y viabilizar el uso de enzimas, para su procesamiento.

\section{MATERIALES Y MÉTODOS}

Material vegetal. Se muestrearon y seleccionaron aleatoriamente frutos maduros sanos de cacao (Theobroma cacao $L$.), variedad trinitario clon ICS-60, procedentes de un huerto clonal, de tres años de edad, de la Universidad de los Llanos -sede Barcelona-, de la ciudad de Villavicencio, Meta (Colombia), ubicada en las coordenadas latitud 404'33.78”N, longitud $73^{\circ} 34^{\prime} 49.50 " O$, altitud $441 \mathrm{msnm}$, con clima cálido, humedad relativa superior al $70 \%, 3856 \mathrm{~mm}$ precipitaciones anuales y temperatura media anual de $25,5^{\circ} \mathrm{C}$. Los frutos fueron lavados y despulpados para la obtención de las cáscaras de la mazorca, las cuales, fueron sometidas a un proceso de escaldado, por 10 minutos, a $90^{\circ} \mathrm{C}$, previo al proceso de extracción para inactivación de enzimas presentes naturalmente. Los procesos de extracción y caracterización, se llevaron a cabo en los laboratorios de Química e Ingeniería Agroindustrial de la Universidad de los Llanos -sede Barcelona-.

Extracción de Pectina. Se realizaron, a escala de laboratorio, en beakers de $1000 \mathrm{ml}$, con cinco tratamientos de hidrólisis por quintuplicado, de la siguiente manera: To: $0 \mu \mathrm{L}$; testigo $\mathrm{T}_{1}: 16,5 \mu \mathrm{L}, \mathrm{T}_{2}: 49,5 \mu \mathrm{L}$ y $\mathrm{T}_{3}: 82,9 \mu \mathrm{L}$, del complejo enzimático 
comercial Viscozyme L, por cada $100 \mathrm{~g}$ de material vegetal; de acuerdo a la ficha técnica de aplicación del fabricante, se utiliza un rango de 0,2 a $1 \mathrm{~kg}$, por cada tonelada de materia prima, por lo cual, se calcularon para $100 \mathrm{~g}$ de cáscara de cacao valores: mínimo, $\mathrm{T}_{1}$; intermedio, $\mathrm{T}_{2}$ y máximo, $\mathrm{T}_{3}$ del complejo, a una temperatura de $50^{\circ} \mathrm{C}$ y pH de 5 (Novozymes, 2009) y $\mathrm{T}_{4}$, hidrólisis ácida, con $\mathrm{HCl} 1 \mathrm{~mol} / \mathrm{L}, 90^{\circ} \mathrm{C}$ y a pH 2. Se estableció el tiempo de extracción de una hora para todos los tratamientos; la precipitación de la pectina se realizó con etanol, al $96 \%$, adicionando $3 / 4$ al volumen de solución péctica, por 30 minutos; la pectina, se filtró en tela muselina y se secó en horno, hasta obtener peso constante (Ferreira et al. 1995).

El rendimiento de la pectina extraída, se calculó en base seca de materia prima, por quintuplicado, de acuerdo al método de Seggiani et al. (2009):

$$
\% \text { de Rend }=\frac{\text { Pectina Pura }(\mathrm{g})}{\begin{array}{c}
\text { Peso prom. de cáscaras en } \\
\text { base seca }(\mathrm{g})
\end{array}} \quad \text { x } 100 \%
$$

Donde, la cantidad de "pectina pura" se calculó libre de humedad y de cenizas. Para determinar el contenido de humedad promedio, se secaron $100 \mathrm{~g}$ de cáscara de mazorca de cacao a $100^{\circ} \mathrm{C}$, hasta obtener peso constante, mientras que el contenido de cenizas, se obtuvo por calcinación de un gramo de pectina a $500^{\circ} \mathrm{C}$, por 24 horas (Chan \& Choo, 2013). Estas determinaciones se realizaron por quintuplicado.

Caracterización fisicoquímica. Se realizó, de acuerdo a la metodología planteada por Owens et al. (1952), aplicándolo al tratamiento con mayor rendimiento de extracción y a las pectinas comerciales de gelificación lenta y rápida por triplicado.

La acidez libre (AL) y el peso equivalente (PE) de la pectina, se determinaron realizando una titulación con Hidróxido de sodio $0,1 \mathrm{~mol} / \mathrm{L}$;éstos, se calcularon relacionando el peso de la muestra $(\mathrm{mg})$ y los miliequivalentes de hidróxido de sodio gastados en la titulación, de acuerdo a las siguientes expresiones (Owens et al. (1952):

$$
\text { Peso equivalente }(\mathrm{Pe})=\frac{\text { mg componente ácido }}{\operatorname{meq}(\mathrm{A}) \mathrm{NaOH}}
$$

Donde:

- Meq A (NaOH): meq de $\mathrm{NaOH}$ utilizados en la titulación

- Componente ácido: mg de pectina

$$
\text { Acidez libre }(\mathrm{Al})=\frac{\operatorname{meq} \mathrm{A}(\mathrm{NaOH})}{\mathrm{g} \text { componente ácido }}
$$

Donde:

- Meq A (NaOH): meq de $\mathrm{NaOH}$ utilizados en la titulación

- Componente ácido: mg de pectina
El porcentaje de Metóxilo, se determina con la solución empleada para la determinación del peso equivalente y acidez, en la cual, se agrega hidróxido de sodio $0,25 \mathrm{~mol} / \mathrm{L}$, para desesterificar la pectina; la solución se neutraliza con ácido clorhídrico $0,25 \mathrm{~mol} / \mathrm{L}$ y se titula con hidróxido de sodio $0,1 \mathrm{~mol} / \mathrm{L}$, para determinar el porcentaje de metóxilo, hasta el viraje de color a rojizo, que se calcula por medio de la ecuación (4):

$$
\% \text { Metoxilo (Me) } \frac{\text { meq B } * 31 * 100}{\text { mg componente ácido }} \quad \text { (Ec. 4) }
$$

Donde:

- 31: peso molecular del metóxilo $\left(\mathrm{CH}_{3} \mathrm{O}\right)$ expresado en $\mathrm{mg} / \mathrm{meq}$

- meq B: meq de $\mathrm{NaOH}$ utilizados en la titulación

- Componente ácido: Peso de la muestra (mg)

El grado de esterificación, se calcula relacionando los meq B gastados en la titulación de determinación del porcentaje de metoxilación y la suma del total de los meq A gastados en la titulación de determinación del peso equivalentes y meq $\mathrm{B}$, de acuerdo a la ecuación (5):

\% Grado de esterificación $(\mathrm{Ge})=\frac{\text { meq B }}{\text { meq } A+\text { meq B }} \quad$ (Ec. 5)

Donde:

- meq A: miliequivalentes utilizados en la primera titulación $\mathrm{NaOH} 0,1 \mathrm{~mol} / \mathrm{L}$

- meq B: miliequivalentes utilizados de $\mathrm{NaOH} \mathrm{0,1} \mathrm{mol/L} \mathrm{en} \mathrm{la}$ segunda titulación para determinar el contenido de metóxilo

El porcentaje de ácido anhídrido galacturónico (AAG) permite conocer el grado de pureza de la sustancia péctica, debido a que la pectina es un polisacárido constituido no solo por ácido D-galacturónico, sino también, en su estructura, el $10 \%$ o más de la cadena puede representar otros azúcares, como arabinosa, glucosa y ramnosa.

Su determinación es la acidez libre y unidades metiladas, relacionándolos en la ecuación (6):

$\% \mathrm{AAG}=\frac{176 * 100-(\text { meq } \mathrm{A}+\text { meq } \mathrm{B})}{\text { mg componente ácido }}$

Donde:

- 176: Peso molecular del ácido anhídrido galacturónico expresado en $\mathrm{mg} / \mathrm{meq}$

- meq A: miliequivalentes utilizados en la primera titulación con $\mathrm{NaOH} 0,1 \mathrm{~mol} / \mathrm{L}$

- meq B: miliequivalentes utilizados de $\mathrm{NaOH} \mathrm{0,1} \mathrm{mol/L} \mathrm{en}$ la segunda titulación, para determinar el contenido de metoxilo

- Componente ácido: peso de la muestra (mg) 
Prueba de viscosidad aparente. Se preparó una conserva de fruta dulce, tipo mermelada, con pulpa de piña, variedad oro miel, utilizando, como aditivos, gelificantes pectina comercial (P.C.), de gelificación rápida (pectina rápida 105) y pectina extraída de la cáscara de la mazorca de cacao (P.E.), bajo la siguiente formulación estándar: $200 \mathrm{~g}$ de pulpa, $200 \mathrm{~g}$ de azúcar, $40 \mathrm{~mL}$ de agua, $5,4 \mathrm{~g}$ de pectina y $25 \mathrm{mg}$ de cloruro de calcio (este último, se aplicó teniendo como referencia que la pectina obtenida de cacao es de bajo metóxilo en investigaciones de Vriesmann et al. (2011). Los componentes, se pesaron y se mezclaron con agitación constante, se llevó a temperatura de ebullición $\left(98^{\circ} \mathrm{C}\right)$, por 45 minutos y se dejó en reposo, hasta enfriamiento. Las mediciones, se realizaron en un viscosímetro rotacional Fungilab Adv Series ${ }^{\circledR}$ con husillo R3, registrando 3 mediciones de viscosidad, cada 2 minutos, en cada velocidad de deformación utilizada.

Análisis estadístico. El proceso de extracción de pectina, se realizó por quintuplicado y fueron sometidos a la prueba de Kolmogorov-Smirnov, para verificar su normalidad. Posteriormente, se aplicó un análisis de varianza (ANDEVA) de una vía y pruebas de comparación de medias de Tukey, a un nivel de confianza del $95 \%$.

\section{RESULTADOS Y DISCUSIÓN}

Extracción de pectina. El rendimiento de extracción de pectina demostró un mínimo promedio de 9,9\% $\pm 0,3\left(\mathrm{~T}_{1}\right)$ y máximo promedio de $13 \%+0,5\left(\mathrm{~T}_{3}\right)$. El análisis de varianza y la prueba de comparación de medias de Tukey (95\%) permi- tieron evidenciar diferencias significativas individuales entre los tratamientos, encontrándose los mayores rendimientos de extracción de pectina a mayores concentraciones del complejo enzimático (Figura 1). Se observa, dentro de los tratamientos enzimáticos una relación incremental de tipo lineal, entre el porcentaje de rendimiento y la concentración, como sigue:

$\%$ Rendimiento $=5[\mathrm{E}]+8,77$

Dónde: [E] es la concentración del complejo enzimático, evidenciándose un aumento estimado de $5 \%$ por cada $\mu \mathrm{L}$ de complejo enzimático/g cáscara, utilizado en la extracción. En cuanto a la calidad de este ajuste, se puede decir que el 98,97\% de la variación observada en el porcentaje de rendimiento de extracción es explicada por el modelo de tipo lineal, lo que indica que la calidad del ajuste es satisfactorio y que, por ello, la relación entre el porcentaje de rendimiento y la concentración de complejo enzimático $[E]$ es descrita adecuadamente por una línea recta de tipo incremental, dadas las condiciones evaluadas. Por otro lado, a partir de este comportamiento, se infiere que a bajas concentraciones de enzima se produjo una posible saturación de los sitios activos, que impiden alcanzar, durante ese tiempo, un mayor rendimiento en el proceso de extracción (Yuan et al. 2003). De igual manera, se pudo observar que las extracciones vía enzimática mostraron rendimientos significativamente mayores a los obtenidos con hidrólisis ácida $\left(\mathrm{T}_{4}\right) 3,7 \%$. Algunos autores han reportado rendimientos de extracción con hidrolisis ácida de 26,3\%, con otro tipo de residuos, como la cáscara de limón, a una concentración $0,2 \mathrm{~mol} / \mathrm{L}$ a $70^{\circ} \mathrm{C}$ y

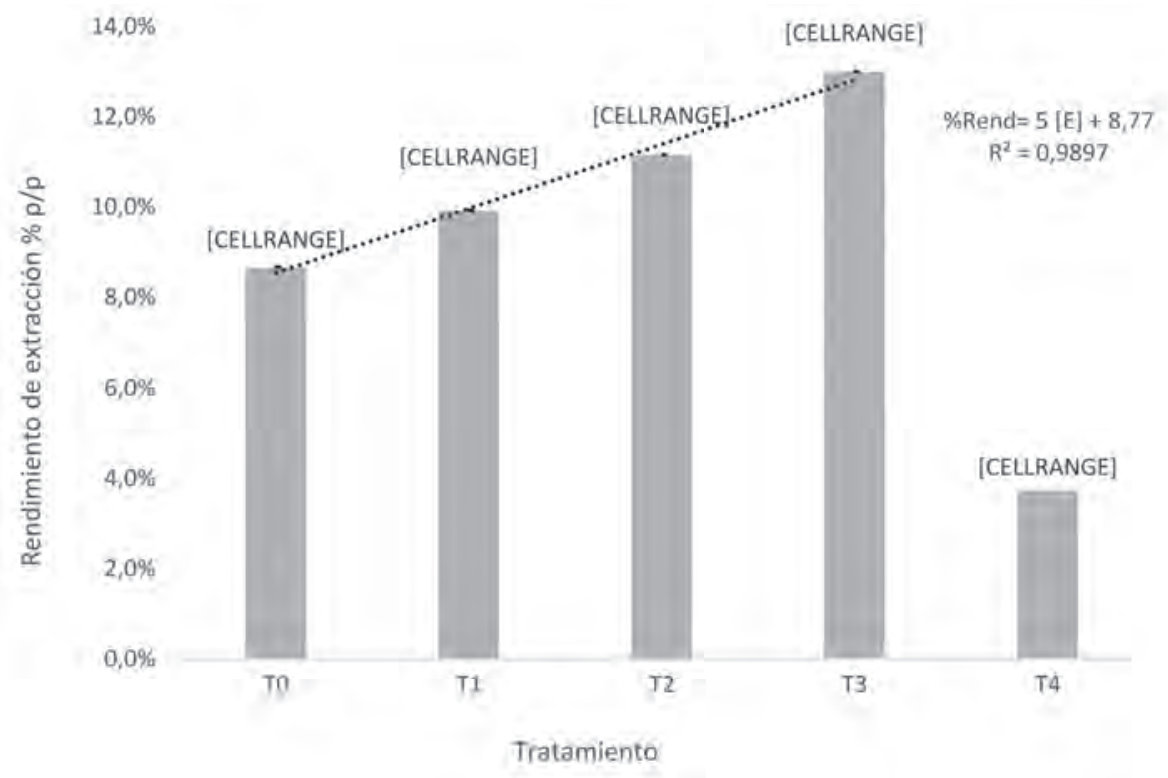

Figura 1. Rendimiento de extracción de pectina en base seca, de los diferentes tratamientos de extracción (letras diferentes entre cada uno de los tratamientos evidencian diferencia significativa $\mathrm{P}<0,05$ ). 
con cáscara de cacao, hasta 5,13\%, a un pH de 2,5, con ácido clorhídrico, $95^{\circ} \mathrm{C}$ y tiempo de 1,5 horas de extracción (Chan \& Choo, 2013; Seggiani et al. 2009); esta diferencia posiblemente se deba, a un tiempo de extracción insuficiente, con este tipo de hidrólisis (Chan \& Choo, 2013). Además, la alta temperatura requerida $\left(95^{\circ} \mathrm{C}\right)$ pudo haber hidrolizado la pectina soluble, rompiendo las cadenas laterales y liberando azúcares, disminuyendo así la calidad y la cantidad de la pectina presente, hasta formar ácidos pécticos sin esterificación (Laguado et al. 1999; Fredes Monsalves et al. 2009); sin embargo, esto evidencia un menor consumo energético con mayor rendimiento utilizando procesos de extracción enzimática a temperaturas más bajas $\left(50^{\circ} \mathrm{C}\right)$, que por hidrólisis ácida $\left(90-95^{\circ} \mathrm{C}\right)$ (Chan \& Choo, 2013; Maldonado Culquimboz et al. 2010).

El costo estimado de utilizar el complejo enzimático comercial, teniendo en cuenta el mayor rendimiento de extracción, representa una inversión alrededor de $\$ 23$ pesos por gramo de pectina extraída, empleando el complejo enzimático, mientras que con ácido clorhídrico $1 \mathrm{~mol} / \mathrm{L}$, se requiere alrededor de $\$ 44$, es decir, que se generaría una reducción del $47,7 \%$ en costo, con mayor rendimiento, aplicando la extracción enzimática.

Caracterización fisicoquímica. La tabla 1 contiene los resultados obtenidos durante la caracterización fisicoquímica de la pectina extraída (P.E) en $T_{3}$. En cuanto al peso equivalente (PE), el cual, corresponde al número de unidades de ácido urónico anhidro y el grado de esterificación, se encontró en la pectina extraída (P.E) valores por encima de los resultados obtenidos para las pectinas comerciales (P.C.) evaluadas, lo que podría indicar presencia de residuos de cáscara de cacao, azúcares o sustancias polifenólicas, causado, probablemente, por la actividad xilanasa, celulasa y hemicelulasa del complejo enzimático (Novozymes, 2009), donde la actividad endo-beta glucanasa hidroliza los enlaces (1-3) o (1-4) en beta-D-glucanos, liberando ácidos, azúcares y metabolitos, atrapados en la matriz polimérica (Kashyap et al. 2001).

Tabla1. Caracterización fisicoquímica de las pectinas comerciales y la pectina extraída del tratamiento $T_{3}$.

\begin{tabular}{|l|c|c|c|c|c|}
\hline Muestra & $\begin{array}{c}\text { PE } \\
(\text { MG/MEQ })\end{array}$ & $\begin{array}{c}\text { AL } \\
(\mathbf{m e q} / \mathbf{g})\end{array}$ & $\%$ ME & \%GE & \% AAG \\
\hline Pectina comercial gelificación lenta & $2702,9 \pm 54,4_{\mathrm{a}}$ & $0,37 \pm 0,0_{\mathrm{a}}$ & $2,23 \pm 0,0_{\mathrm{a}}$ & $66 \% \pm 0,0_{\mathrm{a}}$ & $19,2 \pm 0,1_{\mathrm{a}}$ \\
\hline Pectina comercial, gelificación rápida & $3602,1 \pm 37,1_{\mathrm{b}}$ & $0,28 \pm 0,0_{\mathrm{b}}$ & $2,90 \pm 0,0_{\mathrm{b}}$ & $77 \% \pm 0,0_{\mathrm{b}}$ & $21,3 \pm 0,4 \mathrm{~b}$ \\
\hline Pectina (T3) & $5091,4 \pm 77,6_{\mathrm{c}}$ & $0,20 \pm 0,01_{\mathrm{c}}$ & $1,58 \pm 0,01_{\mathrm{c}}$ & $72 \% \pm 0,1_{\mathrm{c}}$ & $12,5 \pm 1,0_{\mathrm{c}}$ \\
\hline
\end{tabular}

(Letras diferentes entre cada uno de los tratamientos evidencian diferencia significativa $\mathrm{P}<0,05$ ).

La acidez libre (AL) presentó valores menores que los obtenidos para las pectinas comerciales sin P.C.; sin embargo, se encuentra dentro de los intervalos reportados para P.E., por hidrólisis ácida (Vriesmann et al. 2011).

El grado de metoxilación (ME) de la P.E. y la comercial fue menor al $7 \%$, clasificándose como pectinas de bajo metóxilo, lo que concuerda con los resultados reportados por otros autores para pectina obtenida de cáscara de cacao (Chan \& Choo, 2013; Vriesmann et al. 2012); sin embargo, la P.C. pudo haber sufrido una desesterificación con $\mathrm{HCl}$ durante el proceso de neutralización de la saponificación con $\mathrm{NaOH}$ en la titulación de caracterización, pudiendo afectar su porcentaje y disminuyendo así la metoxilación.

Durante la maduración, los tejidos de los frutos presentan una variación del contenido de pectina soluble. En estado inmaduro, la pectina está totalmente esterificada, lo que le confiere mayor rigidez al tejido; en procesos de extracción industrial, se buscan bajos estados de maduración, para obtener mayores rendimientos de pectina, con calidad de alto metóxilo; no obstante, la acción natural de las enzimas sobre los tejidos durante la maduración convierte la protopectina en pectina soluble, ablandando los frutos y disminuyendo el grado de metoxilación, es decir, que los residuos agroindustriales de cáscaras de frutos maduros son una fuente, en menor proporción aprovechable, para la industria agroalimentaria (Fredes Monsalves et al. 2009; Cerón-Salazar \& Cardona-Alzate, 2011).

El grado de metoxilación es un parámetro importante en la industria alimentaria, ya que las pectinas de alto metóxilo requieren presencia de azúcar, entre $60-65 \%$ y pH ácido, entre 2 a 3,5, para formar geles en la elaboración de mermeladas y postres, principalmente, con texturas más rígidas, que aquellas con menor grado de metoxilación. Por otra parte, las pectinas de bajo metóxilo requieren de la presencia de iones de calcio y de $\mathrm{pH}$, entre 2,8 y 6,5, para poder formar estas interacciones, que las hace pectinas de bajo metóxilo, útiles para la industria alimentaria de productos bajos en azúcar (light) o con edulcorantes, que sustituyen la sacarosa con destino a personas con problemas de diabetes (CerónSalazar \& Cardona-Alzate, 2011). 
El grado de esterificación (GE) en las pectinas comerciales P.C. y la P.E. fue mayor a $60 \%$, probablemente, por la presencia de grupos carboxilo esterificados con grupos etoxilos o amidas (Vriesmann et al. 2011), clasificándose dentro del grupo de pectinas gelificación lenta, siendo las más apreciadas dentro de la industria alimentaria, en general, pues a mayor grado de esterificación, se incrementa su viscosidad, importante en el momento de la elaboración de productos, con diversas características de textura (Adi-dako et al. 2016; Chaparro et al. 2015).

El porcentaje de ácido anhídrido galacturónico (AAG) es indicativo del grado de pureza; la P.E. presentó un $12,5 \%$, que representa una pureza baja, comparada con la P.C., dado que la pectina no está constituida solamente por ácido D-galacturónico dentro de su estructura, ya que se encuentran, en menor proporción, otros azúcares, como arabinosa, glucosa y ramnosa (Vriesmann et al. 2011); además, la posible presencia de residuos de cáscara del proceso de filtrado disminuyen su pureza (Vriesmann et al. 2011). Por otro lado, la P.E. mostró una coloración café oscura, que indica la presencia de otras sustancias polifenólicas o metabolitos secundarios, como catequinas, leucocianidinas y taninos, que no se solubilizaron en el proceso de separación de la pectina en la solución péctica, otorgando esta coloración y sabor astringente amargo (Adidako et al. 2016; Vriesmann et al. 2011), requiriendo realizar procesos de purificación, implementando lavados con etanol, debido a que la pectina no es soluble en esta sustancia, mientras que estos metabolitos, se pueden extraen con agua o combinaciones con alcohol o por centrifugación (Adi-dako et al. 2016; Vriesmann et al. 2011; González et al. 2008).
Prueba de viscosidad aparente. De acuerdo a los perfiles de viscosidad aparente (VA) (Figura 2), para las formulaciones evaluadas realizadas, la VA máxima (velocidad de deformación: 3rpm) y mínima (velocidad de deformación: 50rpm) con P.E. de las cáscaras de la mazorca de cacao fue de $6043,7 \mathrm{mPa} . \mathrm{s}$ y $1741,3 \mathrm{mPa} . \mathrm{s}$, respectivamente, mientras que para la P.C., la viscosidad aparente máxima fue de 7616,1mPa.s y mínima, de 2019,1mPa.s, observándose menor poder de gelificación con la P.E, con mayores diferencias en las viscosidades aparentes, obtenidas entre las velocidades 12 y $30 \mathrm{rpm}$, debiéndose estas diferencias, principalmente, al grado de esterificación y de metoxilo, entre las pectinas evaluadas (Tabla 1) (Chaparro et al. 2015).

En ambos casos, la viscosidad aparente presentó un comportamiento de fluido no Newtoniano, con un comportamiento de tipo exponencial decreciente. Ecuaciones 8 y 9 :

$\mu=14059 \Omega^{-0,488}$ para la pectina comercial

$\mu=9960,6 \Omega^{-0,463}$ para la pectina extraída

Donde $\mu=$ viscosidad aparente (mPa.s) y $\Omega=$ velocidad del husillo (rpm)

Ambos modelos presentaron un coeficiente de determinación por encima de 0,97, demostrando una buena explicación de los datos experimentales por medio del modelo, en donde se puede observar que la viscosidad disminuye al aumentar la fuerza de rotación (Figura 2), característico de un fluido independiente del tiempo con cualidades pseudoplásticas (Rao, 2014; Silva et al. 2008).

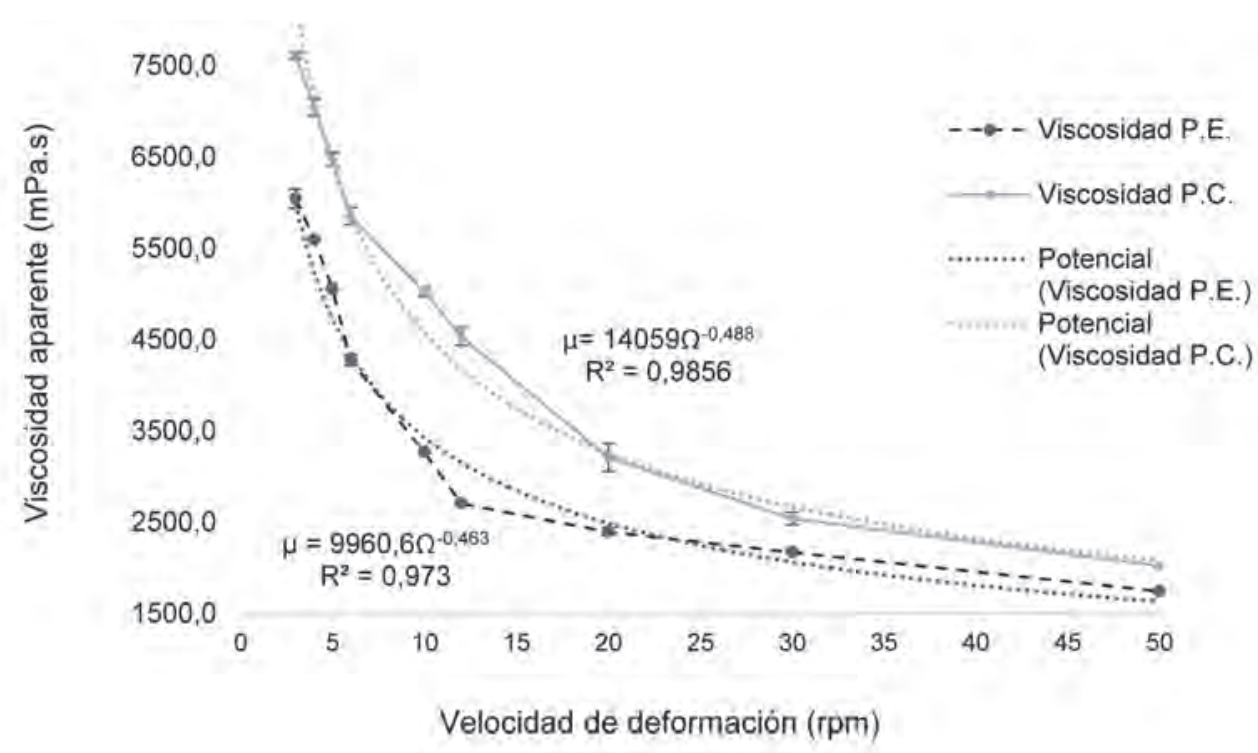

Figura 2. Comportamiento de la viscosidad aparente del producto comercial, elaborado con pectina comercial (P.C) y la pectina extraída (P.E). 
En conclusión, la aplicación del método enzimático presentó mayor rendimiento de extracción en comparación con hidrólisis ácida. De acuerdo con los resultados obtenidos en la caracterización fisicoquímica es de bajo metóxilo y puede ser utilizada en la industria alimentaria, empleando, como sustrato, las cáscaras de cacao, con una diferencia de 9,3 puntos porcentuales, reducción de costos del 47,7\% y menor consumo energético, al utilizar una temperatura óptima de trabajo de $50^{\circ} \mathrm{C}$, para las enzimas, muy por debajo de la empleada en hidrólisis ácida, de $90^{\circ} \mathrm{C}$. Las aplicaciones industriales se orientan, principalmente, al sector alimentario, en productos bajos en azúcar, por ser pectinas de bajo metóxilo.

Con esta investigación, se pudo demostrar que el procesamiento enzimático de este subproducto cacaotero, proporciona una alternativa viable para la obtención de pectina, con propiedades de interés en la industria alimentaria; sin embargo, se sugiere realizar trabajos, donde se mejoren los procesos de purificación, que conlleven a mejorar su calidad.

Agradecimientos: Los autores agradecen a la dirección general de investigaciones de la Universidad de los Llanos, por la financiación de parte de este proyecto, referenciado con código C04-F01-002-2015 y al estudiante Camilo Sarmiento, por su ayuda en la fase experimental. Conflicto de intereses: El manuscrito fue elaborado y revisado por todos los autores, quienes declaramos que no existe conflicto de intereses que ponga en riesgo la validez de los resultados presentados.

\section{BIBLIOGRAFÍA}

1. ADI-DAKO, O.; OFORI-KWAKYE, K.; MANSO, S.F.; BOAKYE-GYASI, M.E.; SASU, C.; POBEE, M. 2016. Physicochemical and antimicrobial properties of cocoa pod husk pectin intended as a versatile pharmaceutical excipient and nutraceutical. J. Pharmaceutics (UK). 12p.http://doi.org/10.1155/2016/7608693.

2. BRETT, C.; WALDRON, K. 1990. Cell-wall degradation. In: Black, M.; Chapman, J. (Eds.), Physiology and Biochemistry of Plant Cell Walls.Dordrecht.Springer. (Netherlands). p.168-179.

3. CERÓN-SALAZAR, I.; CARDONA-ALZATE, C. 2011. Evaluación del proceso integral para la obtención de aceite esencial y pectina a partir de cáscara de naranja. Ingeniería y Ciencia. (Colombia). 7(13):65-86.

4. CHAN, S.-Y.; CHOO, W.-S. 2013. Effect of extraction conditions on the yield and chemical properties of pectin from cocoa husks. Food Chemistry. (UK). 141(4):3752-3758.
5. CHAPARRO, S.; MÁRQUEZ, R.; SÁNCHEZ, J.; VARGAS, M.; GIL, J. 2015. Extracción de pectina del fruto del higo (Opuntia ficus indica) y su aplicación en un dulce de piña. Rev. U.D.C.A Act. \&Div. Cient. (Colombia). 18(2):435-443.

6. CHASQUIBOL SILVA, N.; MORALES GOMERO, J.C. 2010. Contribución al estudio del proceso de gelación de la pectina del níspero de la sierra. Ingeniería Industrial. (Perú). 28:157-176.

7. FEDECACAO. 2015. Producción Nacional de Cacao en grano por departamentos 2002-2014. Disponible desde Internet en: http:/www.fedecacao.com.co/ portal/index.php/es/2015-02-12-17-20-59/nacionales (con acceso el 27/02/2016).

8. FERREIRA, S.; PERALTA N., A.P.; RODRÍGUEZ A., G.P. 1995. Obtención y caracterización de pectina a partir de desechos industriales del mango (cáscara). Rev. Col. Cienc. Químico-Farmacéuticas. 24:29-34.

9. FREDES MONSALVES, C.; LOYOLA LÓPEZ, N.; MUÑOZ CRUZ, J.C. 2009. Extracción de pectinas de Vitis labrusca CV. Concord para producir jaleas. Idesia (Arica). (Chile), 27(3):9-14.

10. GONZÁLEZ-NEVES, G.; FAVRE, G.; CHARAMELO, D.; BALADO, J.; BARREIRO, L.; BOCHICCHIO, R.; TESSORE, A. 2008. Estudio comparativo de la extracción de polifenoles en la elaboración de vinos Tannat por técnicas alternativas. Rev. Enología. (Argentina), 1(5):1-5.

11. INTERNATIONAL COCOA ORGANIZATION. 2012. International Cocoa Organization. Disponible desde Internet en: https:/www.icco.org/statistics/production-and-grindings/production.html (con acceso el 27/02/2016).

12. JAIMES SUÁREZ, Y.; ARANZAZU HERNÁNDEZ, F. 2010. Manejo de las enfermedades del cacao (Theobroma cacao L.) en Colombia, con énfasis en monilia (Moniliophthora roreri). Fedecacao. (Colombia), 90p. Disponible desde Internet en: http://www.fedecacao.com.co/site/images/recourses/pub_doctecnicos/fedecacao-pub-doc_04A.pdf (con acceso el 25/04/2016).

13. KASHYAP, D.R.; VOHRA, P.K.; CHOPRA, S.; TEWARI, R. 2001. Applications of pectinases in the commercial sector: a review. Bioresource Technol. (UK). 77(3):215-227. 
14. KHANAHMADI, S.; YUSOF, F.; CHYUAN ONG, H.; AMID, A.; SHAH, H. 2016. Cocoa pod husk: A new source of CLEA-lipase for preparation of low-cost biodiesel: An optimized process. J. Biotechnology. (Netherlands). 231:95-105.

15. LAGUADO, N.; PÉREZ, E.; ALVARADO, C.; MARÍN, M. 1999. Características fisicoquímicas y fisiológicas de frutos de guayaba de los tipos Criolla Roja y San Miguel procedentes de dos plantaciones comerciales. Rev. Facultad de Agronomía. (Colombia). 16(4):382397.

16. MALDONADO CULQUIMBOZ, Y.; SALAZAR OCAMPO, S.; MILLONES CH, C.; TORRES M., E.; VÁSQUEZ, E. 2010. Extracción de pectina mediante el método de hidrólisis ácida en frutos de maushan (Vasconcellea weberbaueri (Harms) V.M. Badillo) provenientes del distrito de San Miguel de Soloco, región Amazonas. Rev. Aporte Santiaguino. (Perú). 3(2):177-184.

17. MINISTERIO DE AGRICULTURA Y DESARROLLO RURAL. 2012. Plan de Desarrollo Cacaotero 20122021. Colombia. Disponible desde Internet en: http://conectarural.org/sitio/sites/default/files/documentos/Plan\%20Nacional\%20de\%20desarrolo\%20 ca (con acceso el 27/02/2016).

18. NOVOZYMES. 2009. Ficha de Aplicación Alimentos y Nutrición. Viscozyme L para el Procesamiento de Vegetales y Frutas. Generic, Bogotá D.C., Colombia: Novozymes Latin America Ltda.

19. OWENS, H.S.; MCCREADY, R.M.; SHEPHERD, A.D.; MIERS, J.C.; EARLANDSED, R.F.; MACLAY, W.D. 1952. Methods used at western regional research laboratory for extraction and analysis of pectic materials. Book, Albany, California: AIC-340, Western, Regional Research Laboratory.

20. PUA, F. LING; SAJAB, M.S.; CHIA, C.H.; ZAKARIA, S.; RAHMAN, I.A.; SALIT, M.S. 2013. Alkaline-treated cocoa pod husk as adsorbent for removing methylene blue from aqueous solutions. J. Environmental Chemical Engineering. (UK). 1(3):460-465.
21. RAO, M.A. 2014. Rheology of Fluid, Semisolid, and Solid Foods. Boston, MA: Springer US. http://doi. org/10.1007/978-1-4614-9230-6.

22. SEGGIANI, M.; PUCCINI, M.; PIERINI, M.; GIOVANDO, S.; FORNERIS, C. 2009. Effect of different extraction and precipitation methods on yield and quality of pectin. Int. J. Food Sci. Technol. (UK). 44(3):574580.

23. SILVA, N.C.; BENITES, E.A.; GOMERO, J.C.M. 2008. Extracción y caracterización de pectinas obtenidas a partir de frutos de la biodiversidad peruana. Ingeniería Industrial. (Perú). 26:175-199.

24. SYAMSIRO, M.; SAPTOADI, H.; TAMBUNAN, B.H.; PAMBUDI, N.A. 2012. A preliminary study on use of cocoa pod husk as a renewable source of energy in Indonesia. Energy Sustain. Development. (UK). 16:74-77.

25. VRIESMANN, L.C.; DE MELLO CASTANHO AMBONI, R.D.; DE OLIVEIRA PETKOWICZ, C.L. 2011. Cacao pod husks (Theobroma cacao L.): composition and hot-water-soluble pectins. Industrial Crops and Products. (Netherlands). 34(1):1173-1181.

26. VRIESMANN, L.C.; TEÓFILO, R.F.; DE OLIVEIRA PETKOWICZ, C.L. 2012. Extraction and characterization of pectin from cacao pod husks (Theobroma cacao L.) with citric acid. LWT - Food Sci. Technol. (UK). 49(1):108-116.

27. WILLATS, W.G.T.; MCCARTNEY, L.; MACKIE, W.; KNOX, J.P. 2001. Pectin: Cell biology and prospects for functional analysis. Plant Molecular Biology. (Netherlands). 47(1-2):9-27.

28. YUAN, Z.; ZHAO, J.; WANG, Z.-X. 2003. Flexibility analysis of enzyme active sites by crystallographic temperature factors. Protein Engineering. (United States). 16(2):109-114.

Recibido: Septiembre 28 de 2016

Aceptado: Abril 7 de 2017

\section{Cómo citar:}

Mendoza-Vargas, L.; Jiménez-Forero, J.; Ramírez-Niño, M. 2017. Evaluación de la pectina extraída enzimáticamente a partir de las cáscaras del fruto de cacao (Theobroma cacao L.). Rev. U.D.C.A Act. \& Div. Cient. 20(1): 131-138. 